\title{
The detèction of impending failure in implanted pacemakers
}

\author{
J. G. DAVIES AND HAROLD SIDDONS
}

From St. George's Hospital, London, S.W.I

As implantable pacemakers last a variable time, it is desirable to be able to foretell when each individual pacemaker is nearing the end of its life. A test which detects a number of different impending electronic failures including battery depletion is described. The test requires only standard laboratory equipment and has been used for four years as a three-monthly procedure in an out-patient clinic. In 17 of 19 consecutive patients the test has enabled a change of pacemaker to be carried out electively, rather than after an arbitrary period or as an emergency when pacing has failed.

Present-day fixed-rate pacemakers have a high standard of reliability, but occasional faults occur. Unexpected failure may well be disastrous in a patient who does not take over.

The test described here, which requires only standard electronic equipment, has been used at our Pacemaker Clinic on all patients attending with implanted pacemakers since August 1964. Patients have usually attended at three-monthly intervals, but they are instructed to come earlier if the pacemaker rate alters more than a few beats a minute or if there are symptoms suggesting intermittent or complete failure of pacing. The pacemakers studied in this way were designed at St. George's Hospital by one of us (J. G. D.) ${ }^{1}$ and several years of experience had to be accumulated before the significance of the various readings could be regarded as meaningful. It is now possible to forestall pacing failure by changing the unit when pacing is apparently continuing satisfactorily but the oscilloscope readings indicate impending failure. At St. George's Hospital 17 pacemakers have been changed electively before pacing has failed out of the last 19 changes required for battery depletion or other electronic causes. The technique detects not only battery depletion but, when we were using USCI electrode 'catheters', it enabled us on several occasions to forestall impending wire fractures.

Several other methods of detecting battery depletion of implanted pacemakers have been tried but have proved of little value. Early models designed by us and by others were constructed so

\footnotetext{
'Devices St. George's pacemakers supplied by P. J. Reynolds Ltd.
}

that as the battery voltage fell the rate increased, and it was hoped that speeding a few points would give warning of the necessity of unit change. Experience from various clinics with different makes of pacemaker soon showed the danger of this policy. Increase of voltage drop occurs rather rapidly towards the end of battery life and, coupled with raised impedance of the batteries, causes this speeding to be relatively sudden. The 'runaway' pacemaker stimulating at a high rate soon became recognized as a serious risk (Siddons and Sowton, 1967) and provoked fatal fibrillation in a number of cases. Greatbatch and his colleagues (Chardack, Gage, Federico, Schimert, and Greatbatch, 1964) developed a technique of estimating potential battery life by radiography of the unit in situ, but the technique does not provide a precise indication and requires a radiograph in the exact axis of the batteries, and we have been unable to obtain sufficient film detail.

\section{THE METHOD}

The pacemaker stimulus is recorded on a generalpurpose measuring oscilloscope, using E.C.G. limb electrodes. The E.C.G. electrodes selected for recording are those in line with the stimulating electrodes, e.g., measurements are taken between the right and left arms if the indifferent electrode is in the axilla for a unipolar system (Davies and Sowton, 1964). This technique gives a maximum reading and it has been found to be relatively unaffected by respiration and posture. The impulse is photographed and the following parameters are recorded: maximum amplitude, amplitude at $0.4 \mathrm{~m}$./ $\mathrm{sec}$, , and pulse width. The maxi- 
mum amplitude varies from patient to patient and is dependent upon the distance apart of the pacing electrodes as well as the recording electrodes. Readings vary from $2 \mathrm{mV}$ with bipolar electrodes to 400 $\mathrm{mV}$ with the indifferent electrodes in the right axilla. The arbitrary point $0.4 \mathrm{msec}$. was chosen for the second amplitude measurement because some pacemakers had pulses as short as $0.45 \mathrm{msec}$. This parameter is shown by the vertical dotted line $\left(V_{1}\right)$ in Figure 1. The various readings are compared with

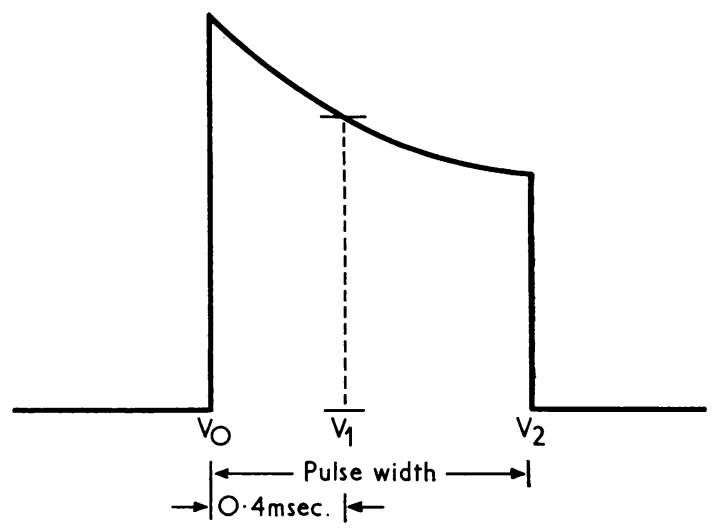

FIG. 1. Diagram of pacemaker impulse recorded from an oscilloscope showing the parameters that are measured.

previous readings from the same patient. The pulse trailing edge $\left(V_{2}\right)$ has not been found to be significant.

Figure 2 shows that pacemakers of different voltages produce a correspondingly different millivoltage pick-up on oscilloscopic test from a patient. (This only applies to pacemakers of the 'constant voltage' type, such as the Devices models.) Thus, initial amplitude $\left(\mathrm{V}_{\mathrm{o}}\right)$ of the impulse bears a direct relationship to the output power; a significant drop from previous readings $(30 \%$ with a Devices pacemaker) suggests

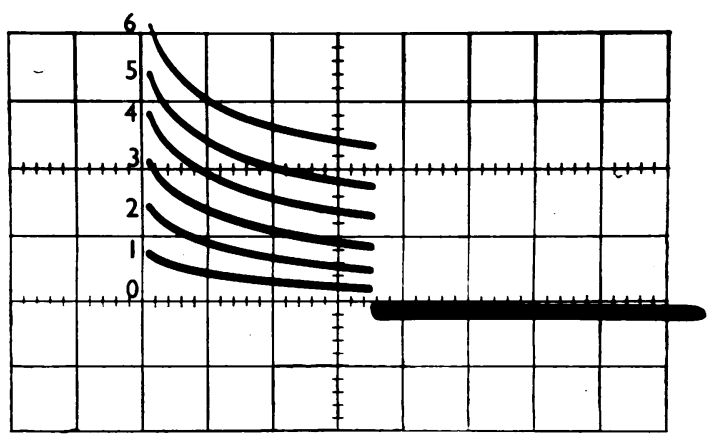

FIG. 2. A recording of the pacemaker impulse from a patient showing the change in amplitude as the pacemaker output (volts) is varied. that a battery has failed. However, battery depletion is not the only cause in fall of output power; it occurs also with high output impedance resulting from a bad connexion, a transistor change, a high resistance wire, or a break in the insulation of the implanted wire. All these will result in a change in initial amplitude $\left(\mathrm{V}_{\mathrm{o}}\right)$, but some of the various causes may be distinguished by the means indicated in Table I.

T A B L E I

LOCATING FAULT IN A FAILING PACING SYSTEMEXCLUDING GENERATOR

\begin{tabular}{|c|c|c|}
\hline Fault & & Signs \\
\hline Broken wire & . & $\begin{array}{l}\text { Small impulse or none at all-check unit } \\
\text { with a radio and listen for clicks }\end{array}$ \\
\hline Broken insulation & $\cdots$ & Changed vector and pacemaker impulse \\
\hline Fibrosis $\quad \cdots$ & $\ddot{*}$ & $\begin{array}{l}\text { Possible failure to pace-readings constant } \\
0.4 \text { msec. amplitude less than } 75 \%\end{array}$ \\
\hline Sepsis & . & $\begin{array}{l}\text { Possible failure to pace-readings constant } \\
\text { except } 0.4 \text { msec. amplitude usually } \\
85-90 \%\end{array}$ \\
\hline
\end{tabular}

Other faults in the pacing system may be shown up by the $0.4 \mathrm{msec}$. amplitude $\left(V_{1}\right)$. The standard reading using the current electrode system is $62 \%$ of the maximum amplitude $\left(\mathrm{V}_{\mathrm{o}}\right)$. A drop to $85-92 \%$ occurs when there is fluid (usually from sepsis) around the indifferent electrode of an endocardial system. Broken or breaking C50 or 3650 (USCI) ${ }^{2}$ endocardial wires also show a characteristic pattern (Fig. 3). Slight increase in pulse width associated with rate decrease,

\section{T A B L E I I}

ROUTINE READINGS: PACING APPARENTLY SATISFAC-

\begin{tabular}{|c|c|c|}
\hline & Possible Cause & Action \\
\hline $\begin{array}{l}\text { Rate decreased } \\
\text { Pulse width } \\
\text { increased }\end{array}$ & \multirow{2}{*}{$\begin{array}{l}\text { Movement of epoxy resin } \\
\text { affecting transformer or } \\
\text { timing capacitor }\end{array}$} & \multirow{2}{*}{$\begin{array}{l}\text { If rate change is over } \\
10 \% \text {, assess re removal } \\
\text { of pacemaker }\end{array}$} \\
\hline $\begin{array}{l}\text { Rate increased } \\
\text { Pulse width } \\
\text { decreased }\end{array}$ & & \\
\hline $\begin{array}{l}\text { Rate increased } \\
5 \% \\
\text { Pulse width } \\
\text { increased }\end{array}$ & \multirow{2}{*}{$\begin{array}{l}\text { Increase in battery im- } \\
\text { pedance }\end{array}$} & \multirow{2}{*}{$\begin{array}{l}\text { Remove pacemaker: it } \\
\text { is probable that bat- } \\
\text { teries are nearing ex- } \\
\text { haustion }\end{array}$} \\
\hline $\begin{array}{l}\text { Rate decreased } \\
5 \% \\
\text { Pulse width } \\
\text { decreased }\end{array}$ & & \\
\hline $\begin{array}{l}\text { Rate variation } \\
\text { without } \\
\text { change in } \\
\text { pulse width }\end{array}$ & $\begin{array}{l}\text { Timing resistor changed } \\
\text { value or diode failure }\end{array}$ & $\begin{array}{l}\text { If over } 10 \% \text {, remove } \\
\text { pacemaker }\end{array}$ \\
\hline $\begin{array}{l}\text { Fall in maxi- } \\
\text { mum ampli- } \\
\text { tude (leading } \\
\text { edge) }\end{array}$ & $\begin{array}{l}\text { Battery failure, sepsis, } \\
\text { wire failure or high im- } \\
\text { pedance of transistor }\end{array}$ & If $30 \%$, replace \\
\hline
\end{tabular}

2United States Catheter Corp. Inc. 

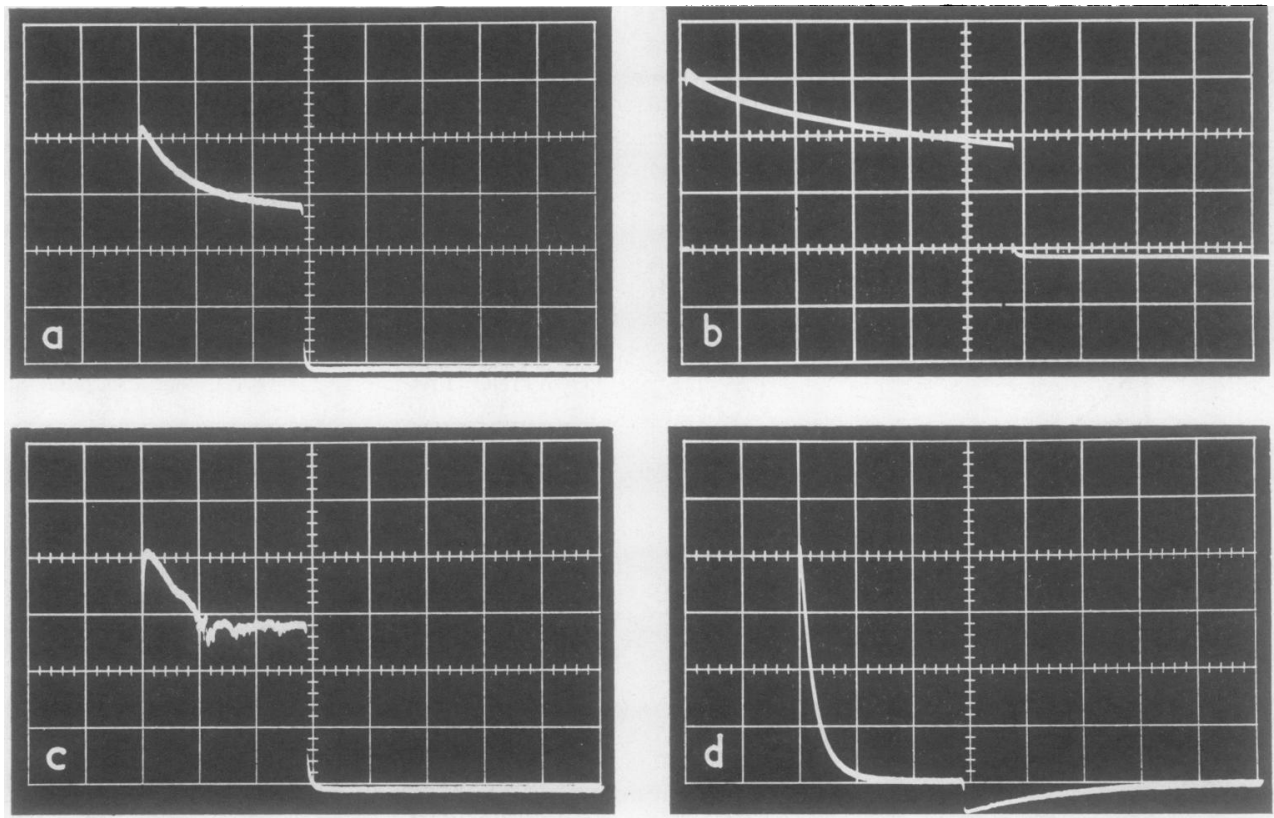

FIG. 3. (a) Normal. (b) An impulse recorded when there was fluid (sepsis) around the indifferent electrode. (c) A fracturing wire giving rise to judder on the impulse. (d) A completely fractured wire with insulation remaining intact.

or vice versa, is usually an indication of stabilizing of the epoxy resin having an effect upon the gap separation of the transformer, and does not call for action. However, if rate and pulse width are both increased or both decreased by more than $10 \%$, this is taken as an indication to remove the pacemaker, as the battery impedance is having an effect on the electronic circuit. A rapidly increasing rate requires urgent removal to avoid pacemaker-induced fibrillation.

These results have been taken only on pacemakers made to our design, and readings on other units may not show the same variations, particularly in pulse height. These tests can be done on bipolar systems, but because respiration and posture affect appreciably electrode alignment, the pulse height measurements are less meaningful ; better results are obtained from unipolar systems. However, it is possible with both systems to measure pulse width and rate, and a check on these two parameters gives a useful indication of pacemaker function.

Table II indicates the interpretation of changes in the readings on routine testing, when pacing is proceeding apparently satisfactorily. Table III sets out the findings in one patient when the oscilloscopic test indicated the necessity of a prophylactic change of a pacemaker which on purely clinical grounds appeared satisfactory.

It is hoped that by means of these tests it will be possible to predict the life of each particular unit. If the method proves reliable with greater $\bar{N}$

T A B L E I I I

RECORDINGS FROM PATIENT W. N.: 'ABDOMINAL' TYPE PACEMAKER MANUFACTURED MARCH 1966

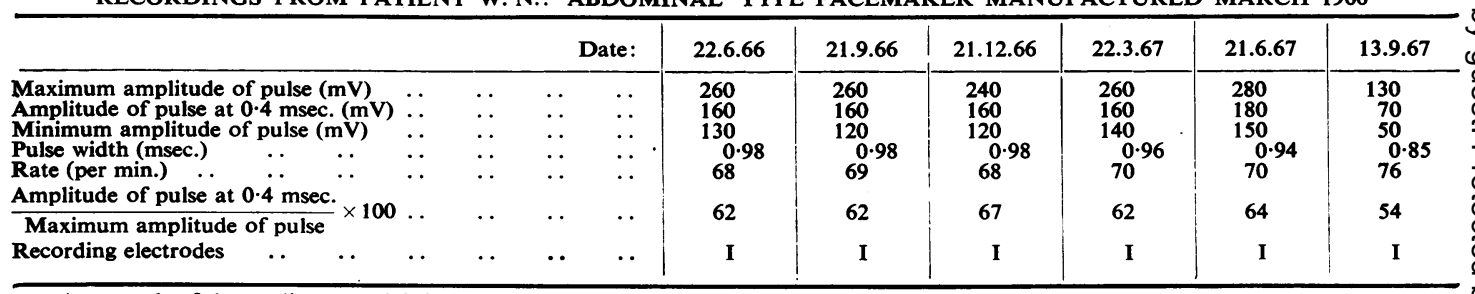

As a result of the readings on 13.9 .67 , the unit was removed and examination revealed two batteries totally exhausted, primary cause not $O$ elucidated. 
experience it should enable each implant to be considered individually so that the unit would be changed when the tests indicated that the pacemaker life was nearing its end rather than having to await failure of pacing or make a change after an arbitrary period of implantation.

Early in the life of a pacemaker it is probably unnecessary to test every three months. However, a change in rate of three or four impulses per minute indicates the need for testing. We suggest that intelligent patients should keep an accurate record of their pulse and report for testing when an alteration of pulse rate is noted rather than at arbitrary intervals.

\section{REFERENCES}

Chardack, W. M., Gage, A. A., Federico, A. J., Schimert, G., and Greatbatch, W. (1964). Clinical experience with an implantable pacemaker. Ann. N.Y. Acad. Sci., 111, 1075.

Davies, J. G., and Sowton, G. E. (1964). Cardiac pacemakers. Phys. in Med. Biol., 9, 257.

Siddons, A. H. M., and Sowton, G. E. (1967). Cardiac Pacemakers. Thomas, Springfield, Ill., U.S.A. 